\title{
THE INFLUENCE OF HYDRATION TIME ON THE Ni UPTAKE BY CEMENT
}

\author{
M. Vespa ${ }^{\left.1,2^{*}\right)}$, R. DÄHN ${ }^{1}$, E. Wieland ${ }^{1}$, D. Grolimund ${ }^{1}$ AND A.M. SCheideGGer ${ }^{1,2}$ \\ ${ }^{1}$ Laboratory for Waste Management, Paul Scherrer Institute, 5232 Villigen PSI, Switzerland \\ ${ }^{2}$ Department of Environmental Sciences, Swiss Federal Institute of Technology (ETH), Zürich, \\ Switzerland
}

In this study, Ni uptake by hardened cement paste has been investigated with the aim of improving our understanding of the immobilization process of $\mathrm{Ni}$ (II) in cement and the influence of the hydration time on the Ni speciation on the microscopic scale. Information on the Ni distribution and speciation of the Ni phases formed in the cement system has been gained by employing synchrotron-based $\mu$-X-ray fluorescence $(\mu$-XRF) and $\mu$-X-ray absorption spectroscopy ( $\mu$-XAS). The Ni-doped cement samples were prepared at a water/cement ratio of 0.4 and with a metal loading of $5000 \mathrm{mg} / \mathrm{kg}$ using a sulphate-resisting Portland cement. The samples were hydrated for six hours and one year to account for the chemical environment in a fresh and aged cement paste, respectively. The $\mu$-XAS measurements reveal that a mixture of $\mathrm{Ni}$ phases is formed at single regions of interests, independent of the hydration time. Data analysis further indicates that $\mathrm{Ni}(\mathrm{II})$ is predominantly immobilized in a layered double hydroxide (LDH, Ni-Al LDH) and only to a minor extent precipitates as Ni-hydroxides. A comparison of the results from this micro-spectroscopic investigation with those from an earlier macro-spectroscopic study, indicate that the same Ni phases are formed both on the macro- and micro-scale.

\section{Introduction}

Cement-based materials have been used worldwide for conditioning radioactive wastes in order to prevent or lower the mobility of the contaminants present in the waste matrices. To ensure the long-term safe disposal of cement-conditioned radioactive waste a deep geological disposal is foreseen for some categories of waste forms [1]. In the radioactive waste, $\mathrm{Ni}$ radioisotopes are mainly associated with irradiated metallic components from nuclear power plants. A molecular-level understanding of the processes governing the immobilization of radionuclides in hydrating cement is essential for detailed predictions of their long-term release from the near field cementations of a repository for radioactive waste. Hardened cement paste (HCP) is a very heterogeneous material with discrete particles in the nano- to micrometer size range. The material consists of mainly calcium (aluminum) silicate hydrates (C-S-H), portlandite (calcium hydroxide) and calcium aluminates. In addition, small amounts of non-hydrated clinker minerals (alite, belite, ferrite aluminate) may be present. The immobilization potential of HCP originates from its selective binding properties for metal cations and anions (e.g. [2]). Thus, it appears that immobilization processes in cement systems are highly specific with respect to the mineral components and mechanisms involved.

\footnotetext{
${ }^{*}$ marika.vespa@psi.ch
} 
In the past, several X-ray absorption spectroscopy (XAS) studies have been reported on the Ni uptake by cement. For example, Scheidegger et al. [3,4] investigated the sorption of $\mathrm{Ni}$ onto hydrated Portland cement. The study showed that a mixture of $\mathrm{Ni}(\mathrm{OH})_{2}$ and Ni-Al layered double hydroxide (Ni-Al LDH, $\left.\left[\mathrm{M}^{\mathrm{II}}{ }_{1-\mathrm{x}} \mathrm{M}^{\mathrm{III}}{ }_{\mathrm{x}}(\mathrm{OH})_{2}\right]^{\mathrm{x}+}\left(\mathrm{A}^{\mathrm{n}-}\right)_{\mathrm{x} / \mathrm{n}} \cdot \mathrm{yH}_{2} \mathrm{O}\right)$ phases was formed. In a recent study, Vespa et al. [5] investigated the Ni speciation during cement hydration by combining XAS measurements on powdered Ni-doped cement material. The authors varied important experimental parameters such as the hydration time, the anions added to the system, the water/cement $(\mathrm{w} / \mathrm{c})$ ratio and the metal concentrations. The XAS study revealed the predominant formation of $\mathrm{Ni}-\mathrm{Al} \mathrm{LDH}$ in the Nidoped cement system and that Ni-hydroxide phases $\left(\alpha-\mathrm{Ni}(\mathrm{OH})_{2}\right.$ and $\left.\beta-\mathrm{Ni}(\mathrm{OH})_{2}\right)$ were present only to a minor extent. The study further showed that the amount of Ni-Al LDH increased as a function of the hydration time, whereas $\alpha-\mathrm{Ni}(\mathrm{OH})_{2}$ decreased and $\beta$ $\mathrm{Ni}(\mathrm{OH})_{2}$ remained constant. The only exception was found in the sample with the lowest Ni-loading (50 mg/kg), in which the precipitation of Ni-Al LDH and Ni-hydroxides phases were not the predominant $\mathrm{Ni}$ species. In a further study, Vespa et al. [6] investigated the influence of the inherent heterogeneity of the cement matrix on the Ni speciation on the micro-scale. The authors focused on the influence of the different Ni loadings on the $\mathrm{Ni}$ speciation in the Ni-doped cement sample hydrated for 30 days. The study demonstrated that the same $\mathrm{Ni}$ speciation observed on the macro-scale is also found on the micro-scale, independent of the Ni-loadings used. This finding indicates that the same $\mathrm{Ni}$ species are relevant both on the micro-scale and for the whole cement matrix.

To further address the question concerning the influence of the hydration time on the Ni speciation micro-level synchrotron-based $\mu$-X-ray fluorescence ( $\mu$-XRF) and $\mu$ extended X-ray absorption fine structure ( $\mu$-EXAFS) were carried out on Ni-doped cement samples, which were hydrated for six hours and one year. This combined approach enables to obtain spatially-resolved information on the Ni distribution and on the chemical speciation of $\mathrm{Ni}$ at selected regions. This information will allow developing a molecular-level understanding of the Ni binding in cement.

\section{Materials and Methods}

\subsection{Sample Preparation}

The cement samples were prepared from a commercial sulphate-resisting Portland cement (CEM I 52.5 N HTS, Lafarge, France) used to condition radioactive waste in Switzerland. Ni-doped HCP was prepared by mixing a $\mathrm{Ni}\left(\mathrm{NO}_{3}\right)_{2}$ solution with unhydrated cement. The metal salt was dissolved in deionized water to obtain stock solutions with concentrations of $0.3 \mathrm{~mol} / \mathrm{L}(\mathrm{pH}=4.5)$. The solutions were mixed with the unhydrated cement at a w/c ratio of 0.4 , using a standard procedure [7]. The final metal concentration of the pastes was $5000 \mathrm{mg} / \mathrm{kg}$ dry HCP. The cement pastes were stored into plexiglass moulds, which were closed with polyethylene lids, and hydrated for six hours and one year. For the short hydration of six hours, the slurry was filtered $(0.2 \mu \mathrm{m}$ pore size) to separate the solid from the free water. The solid material was washed with acetone for 
15 minutes to stop the hydration process [8], filtered and dried in a glovebox under controlled $\mathrm{N}_{2}$ atmosphere $\left(\mathrm{CO}_{2}, \mathrm{O}_{2}<2 \mathrm{ppm}, \mathrm{T}=20 \pm 3{ }^{\circ} \mathrm{C}\right)$. The sample hydrated for one year was stored in a closed container at room temperature at $100 \%$ relative humidity. After hydration was completed, the cylinder was cut into several slices of $\sim 1 \mathrm{~cm}$ thickness and dried in the glovebox in a dry $\mathrm{N}_{2}$ atmosphere. Selected slices from the one year and six hours hydrated samples were impregnated and polished for the preparation of thin sections, which were employed for $\mu$-XRF and $\mu$-EXAFS measurements.

\section{2. $\mu$-XRF and $\mu$-EXAFS data collection and reduction}

$\mu$-XRF and $\mu$-EXAFS data were collected on beamline 10.3.2 at the Advanced Light Source (ALS), Berkeley, USA [9]. The beamline is equipped with a Si(111) crystal monochromator. The monochromator angle was calibrated by assigning the energy of $8333 \mathrm{eV}$ to the first inflection point of the K-edge absorption spectrum of Ni metal foil. The $\mu-$ $\mathrm{XRF}$ and $\mu$-EXAFS measurements were collected at room temperature in fluorescence mode with a 7 element Ge-solid state detector with a beam size of $\sim 5 \times 5 \mu \mathrm{m}^{2}$. The $\mu$-XRF maps were obtained by scanning the sample under the monochromatic beam at the energy of $10000 \mathrm{eV}$ with a pixel size of $5 \times 5 \mu \mathrm{m}^{2}$.

The $\mu$-XRF maps were processed using the Labview software package at the beamline 10.3.2 [9] and MATLAB. $\mu$-EXAFS data at the Ni K-edge were dead-time corrected using the Labview software package at the beamline 10.3.2. Further data reduction was performed using the WinXAS 3.1 software package [10]. All spectra were normalized by fitting a first-degree polynomial to the pre-edge and a third-degree polynomial to the post-edge regions. The energy was converted to photoelectron wave vector units $\left(\AA^{-1}\right)$ by assigning the origin $\mathrm{E}_{0}$ to the first inflection point of the absorption edge. Radial Structure Functions (RSF) were obtained by Fourier transforming the $\mathrm{k}^{3}$-weighted $\chi(\mathrm{k})$ functions between 3.2 and $10.9 \AA^{-1}$ with a Bessel window function with a smoothing parameter of 4 . Multishell fits were performed in real space across the range of the first two shells $(R+\Delta R$ range $=0.8-3.5 \AA)$. Theoretical scattering paths for the fit were calculated using FEFF 8.20 [11] and the structure of $\beta-\mathrm{Ni}(\mathrm{OH})_{2}$ as a reference. The amplitude reduction factor $\left(\mathrm{S}_{0}{ }^{2}\right)$ was determined to be 0.85 from the experimental $\beta-\mathrm{Ni}(\mathrm{OH})_{2}$ EXAFS spectrum [3]. Errors on the structural parameters were estimated from the analysis of two reference compounds $\left(\beta-\mathrm{Ni}(\mathrm{OH})_{2}, \alpha-\mathrm{Ni}(\mathrm{OH})_{2}\right.$; see Table 1$)$. Several reference spectra $\left(\beta-\mathrm{Ni}(\mathrm{OH})_{2}, \alpha-\mathrm{Ni}(\mathrm{OH})_{2}\right.$, synthetic $\mathrm{Ni}-\mathrm{Al} \mathrm{LDH}\left(\mathrm{Ni}: \mathrm{Al}, 2: 1 ; \mathrm{Ni}_{2} \mathrm{Al}(\mathrm{OH})_{6}\left(\mathrm{CO}_{3}\right)_{1 / 2}[12]\right.$, Ni-phyllosilicate [13], neo-formed Ni-Al LDH formed from Ni-doped pyrophyllite [14]), collected at the Swiss Norwegian Beamline (SNBL) at the ESRF, were used to identify the Ni species in the cement matrix.

\section{Results and Discussion}

Fig. 1 shows the elemental distribution of $\mathrm{Ni}$ and $\mathrm{Ca}$ for the 6-hours and 1-year hydrated Ni-doped HCP samples in a $\sim 1000 \times 1000 \mu \mathrm{m}^{2}$ overview map. The regions show a heterogeneous distribution of $\mathrm{Ni}$ and $\mathrm{Ca}$. Both elements reveal higher (red for $\mathrm{Ni}$, white for $\mathrm{Ca}$ ) and lower (blue for $\mathrm{Ni}$, green for $\mathrm{Ca}$ ) concentrated regions. The regions 

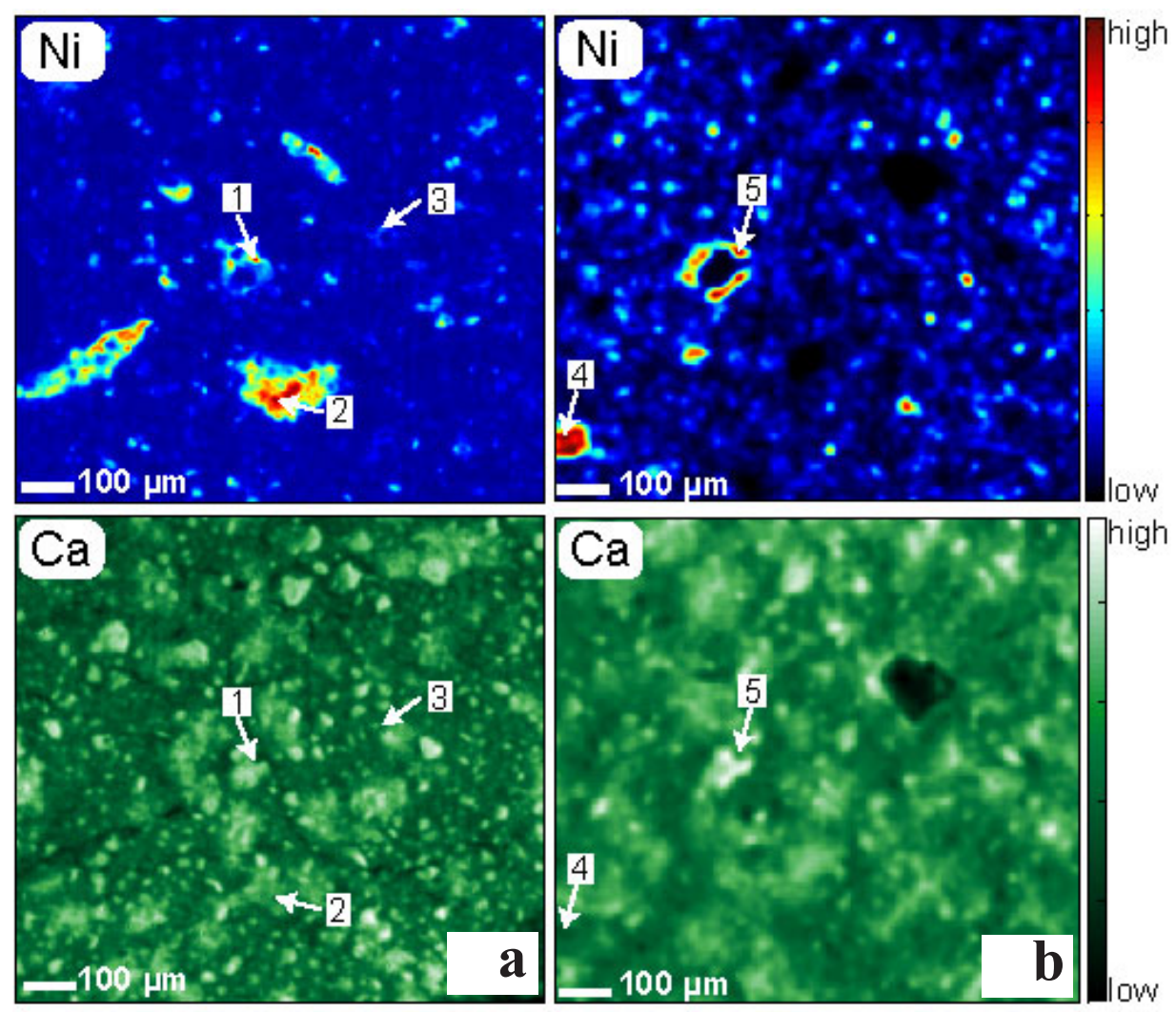

Fig. 1. $\mu$-XRF elemental distribution maps of $\mathrm{Ni}$ and $\mathrm{Ca}$ from the $\mathrm{Ni}\left(\mathrm{NO}_{3}\right)_{2}$-doped $\mathrm{HCP}$ samples with a water/cement 0.4 and a final metal concentration of $5000 \mathrm{mg} / \mathrm{kg}$ with hydration times of a) six hours, and b) one year. Selected spots for $\mu$-EXAFS measurements are marked with numbers from 1 to 5 . The color bar represents relative concentrations in each sample

with high Ca concentration (shown in white) represent the clinker phases, i.e. non-hydrated cement minerals, whereas the lower concentrated regions (shown in green) represent the hydrated cement phases [6]. In the HCP sample (Fig. 1a) hydrated for six hours the amount of non-hydrated clinker phases (shown in white) is higher than in the HCP sample hydrated for one year (Fig. 1b), in which the hydrated cement phases clearly predominate (shown in green). Note that the Ni distribution of these two samples exhibits some differences. It appears that, although both samples have rich (red to yellow areas) and poor (blue areas) Ni regions, the HCP sample hydrated for six hours (Fig. 1a) shows a more uniform distribution of the Ni poor regions compared to the HCP sample hydrated for one year. Moreover, the 1-year-hydrated sample (Fig. 1b) shows regions in which $\mathrm{Ni}$ is depleted (black areas). It also appears that, with increasing hydration time, Ni-rich rims are formed around Ca-rich particles (clinker minerals) as observed for the $\mu$-EXAFS spot 5 (Fig. 1b). By contrast, more homogeneous Ni regions are observed in the HCP 
sample hydrated for six hours (Fig. 1a). Overall, the distribution of Ni reveals a significant anti-correlation with $\mathrm{Ca}$, which is clearly observed in the HCP sample hydrated for one year. Thus, the $\mu$-XRF results, suggest that with increasing hydration time Ni tends to concentrate in specific regions around $\mathrm{Ca}$-rich particles, in particular around the alite clinker mineral as observed from Vespa et al. [6].

The Ni speciation in both samples was determined on various spots at high (red) and low (blue) Ni concentrated regions using $\mu$-EXAFS. Fig. 2 shows selected $\mu$-EXAFS measurements collected at single spots together with the relevant reference spectra. The normalized, background-subtracted and $\mathrm{k}^{3}$-weighted $\mu$-EXAFS spectra of the Ni-doped HCP samples hydrated for six hours and one year are shown (Fig. 2a). All $\mu$-EXAFS spectra of these samples show similar features. For all spots the oscillation at $\sim 4 \AA^{-1}$ reveals a similar position to that of the neo-formed LDH phase, which forms upon Ni uptake by pyrophyllite (N-LDH) [14]. A small feature at $\sim 5 \AA^{-1}$ appears in all experimental spectra, which is well reproduced in both synthetic and neo-formed Ni-Al LDH spectra. The beat pattern at $\sim 8 \AA^{-1}$ shows a splitting of the oscillation. Scheinost and Sparks [15] demonstrated that the beat pattern at $\sim 8 \AA^{-1}$ is an indication for the presence of $\mathrm{Ni}-\mathrm{Al} \mathrm{LDH}$. In fact, this beat pattern is observed
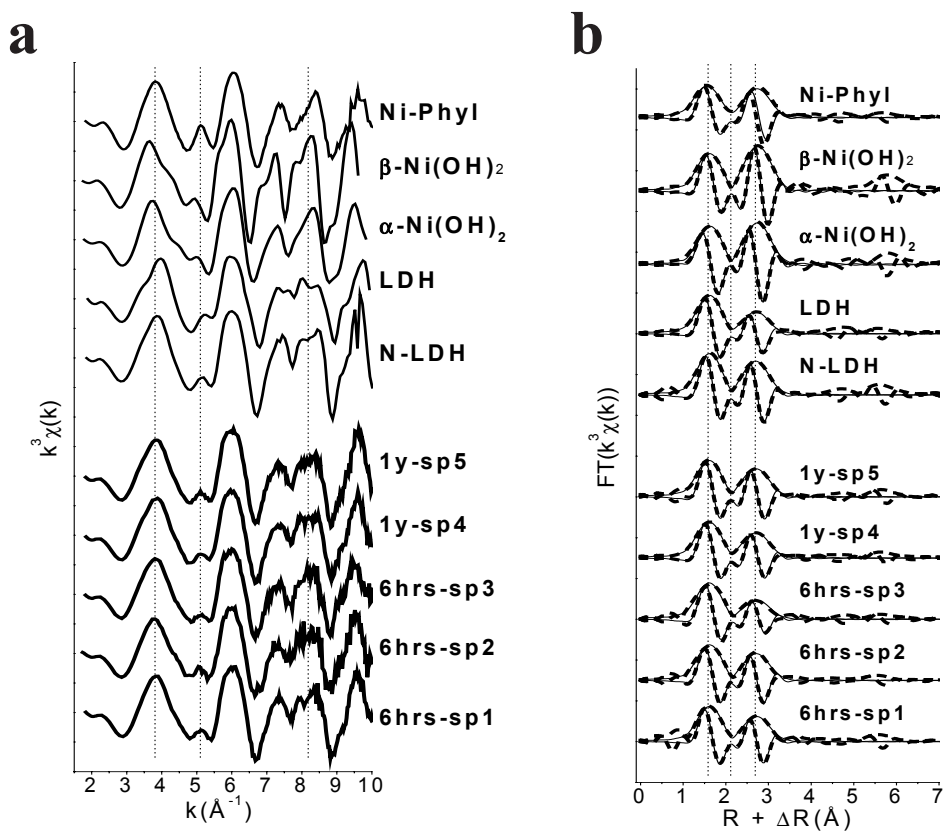

Fig. 2. Ni K-edge spectra for Ni reference compounds and selected $\mu$-EXAFS experimental spectra of the $\mathrm{Ni}\left(\mathrm{NO}_{3}\right)_{2}$-doped $\mathrm{HCP}$ samples with a water/cement 0.4 and a final metal concentration of $5000 \mathrm{mg} / \mathrm{kg}$ hydrated for six hours and one year, a) $\mathrm{k}^{3}$-weighted, normalized, background-subtracted spectra, b) Experimental (solid line) and calculated (dashed line) Fourier Transforms (modulus and imaginary parts) obtained from the $\mu$-EXAFS spectra presented in Fig. 2a. Dotted lines indicate spectral features explained in detail in the text. $\mathrm{sp}=$ spot, $\mathrm{N}-\mathrm{LDH}=$ neo-formed NiAl LDH [14], LDH = synthetic Ni-Al LDH (Ni: Al, 2: 1 [12]), Ni-Phyl = Ni-phyllosilicate [13]. 
Table 1. Structural information obtained from selected $\mu$-EXAFS Ni K-edge data analysis.

(Spots are indicated in Fig. 1)

\begin{tabular}{|c|c|c|c|c|c|c|c|c|c|c|c|}
\hline \multirow[t]{2}{*}{ Sample } & \multicolumn{3}{|c|}{$\mathrm{Ni}-\mathrm{O}$} & \multicolumn{3}{|c|}{$\mathrm{Ni}-\mathrm{Ni}$} & \multicolumn{3}{|c|}{$\mathrm{Ni}-\mathrm{Si}$} & \multirow[t]{2}{*}{$\Delta \mathrm{E}_{0}$} & \multirow[t]{2}{*}{$\% \operatorname{Res}$} \\
\hline & $\mathrm{CN}$ & $\mathrm{R}(\AA)$ & $\sigma^{2}(\AA)$ & $\mathrm{CN}$ & $\mathrm{R}(\AA)$ & $\sigma^{2}(\AA)$ & $\mathrm{CN}$ & $\mathrm{R}(\AA)$ & $\sigma^{2}(\AA)$ & & \\
\hline References & & & & & & & \multirow{14}{*}{3.7} & \multirow{14}{*}{\multicolumn{2}{|c|}{$3.3 \quad 0.008^{\mathrm{d}}$}} & & \\
\hline Ni-Phyllosilicate $^{a}$ & 5.1 & 2.04 & 0.006 & 3.5 & 3.07 & $0.008^{\mathrm{d}}$ & & & & 0.3 & 3.0 \\
\hline$\beta-\mathrm{Ni}(\mathrm{OH})_{2}$ & 5.6 & 2.06 & 0.005 & 5.6 & 3.13 & 0.005 & & & & -0.6 & 3.0 \\
\hline$\alpha-\mathrm{Ni}(\mathrm{OH})_{2}$ & 5.2 & 2.03 & 0.005 & 4.9 & 3.09 & $0.005^{\mathrm{e}}$ & & & & 3.0 & 4.4 \\
\hline Ni-Al LDH (LDH) & 6.0 & 2.05 & 0.006 & 2.5 & 3.06 & $0.005^{\mathrm{e}}$ & & & & 1.1 & 4.5 \\
\hline $\begin{array}{l}\text { Neo-formed Ni-Al LDH } \\
\text { (N-LDH) }\end{array}$ & 5.7 & 2.04 & 0.004 & 3.9 & 3.07 & $0.005^{\mathrm{e}}$ & & & & 0.3 & 3.8 \\
\hline Cement samples & & & & & & & & & & & \\
\hline Ni_cem_6 hrs (bulk-EXAFS) ${ }^{\mathrm{c}}$ & 4.9 & 2.03 & 0.004 & 3.8 & 3.08 & $0.005^{\mathrm{e}}$ & & & & -2.4 & 4.3 \\
\hline spot 1 & 5.8 & 2.05 & 0.006 & 3.3 & 3.08 & $0.005^{\mathrm{e}}$ & & & & 0.4 & 4.4 \\
\hline spot 2 & 5.6 & 2.05 & 0.006 & 3.0 & 3.10 & $0.005^{\mathrm{e}}$ & & & & 1.3 & 6.1 \\
\hline spot 3 & 7.3 & 2.06 & 0.009 & 3.0 & 3.10 & $0.005^{\mathrm{e}}$ & & & & 1.5 & 5.7 \\
\hline Ni_cem_1 y (bulk-EXAFS) ${ }^{c}$ & 6.5 & 2.04 & 0.006 & 3.0 & 3.09 & $0.005^{\mathrm{e}}$ & & & & -1.8 & 4.1 \\
\hline spot 4 & 6.2 & 2.05 & 0.006 & 3.0 & 3.08 & $0.005^{\mathrm{e}}$ & & & & -0.1 & 3.0 \\
\hline spot 5 & 5.5 & 2.05 & 0.005 & 3.3 & 3.08 & $0.005^{\mathrm{e}}$ & & & & -0.2 & 5.3 \\
\hline
\end{tabular}

${ }^{a}$ Scheidegger et al., 1997, ${ }^{b}$ Dähn et al. 2002, ${ }^{\text {c }}$ Vespa et al. 2006, ${ }^{d}$ correlated parameters and ${ }^{\mathrm{e}}$ fix paramaters during fitting procedures.

$\mathrm{R}, \mathrm{CN}, \sigma^{2}, \Delta \mathrm{E}_{0}$ stand for interatomic distances, coordination numbers, Debye-Waller factors and inner potential corrections, respectively. Estimated error: $\mathrm{R}_{\mathrm{Ni}-\mathrm{O}} \pm 0.02 \AA, \mathrm{CN}_{\mathrm{Ni}-\mathrm{O}} \pm 20 \%, \mathrm{R}_{\mathrm{Ni}-\mathrm{Ni}} \pm 0.02 \AA$, $\mathrm{CN}_{\mathrm{Ni}-\mathrm{Ni}} \pm 20 \%$

\% Res: deviation between experimental data and fit given by the relative residual in percent. $\mathrm{N}=$ number of data points, $\mathrm{Y}_{\exp }$ and $\mathrm{Y}_{\text {theo }}$ : experimental and theoretical data points, respectively.

$$
\% \operatorname{Re} s=\frac{\sum_{i=1}^{N}\left|y_{\text {cep }}(i)-y_{\text {thoo }}(i)\right|}{\sum^{N} y_{\text {erp }}(i)} * 100
$$

in both Ni-Al LDH spectra, whereas the other reference compounds $\left(\alpha-\mathrm{Ni}(\mathrm{OH})_{2}, \beta-\mathrm{Ni}(\mathrm{OH})_{2}\right.$ and Ni-phyllosilicate) show an elongated upward oscillation ending in a sharp tip at $\sim 8.5 \AA^{-1}$. Thus, the presence of the beat pattern at $\sim 8 \AA^{-1}$, together with the observed spectral features at $\sim 4 \AA^{-1}$ and $\sim 5 \AA^{-1}$, clearly indicate the presence of a Ni-Al LDH phase. These features appear in all experimental spectra collected at single spots in both Ni-doped HCP samples, indicating that Ni-Al LDH predominantly forms on the micro-scale.

The corresponding Fourier transforms (FT) of the $\mathrm{k}^{3}$-weighted $\mu$-EXAFS spectra are shown in Fig. 2b. The position of the first and second peak of the FT and the shape of the imaginary part reveals strong similarities to the Ni-Al LDH compounds. It should be noted that the amplitude of the second peak in the experimental spectra of the single spots is clearly reduced ([5,15]; see discussion below). This observation also applies for the Ni-Al LDH reference compounds, but not for the other references. This finding corroborates the presence of Ni-Al LDH at the single spots in both Ni-doped HCP samples. This further indicates that $\mathrm{Ni}-\mathrm{Al} \mathrm{LDH}$ already forms in the early stage of the hydration process and that it persists in HCP hydrated for one year. 
The structural parameters derived from multi-shell analysis $(\mathrm{R}+\Delta \mathrm{R}$ range $=0.8-3.5 \AA)$ are summarized in Table 1. The first coordination shell was fitted with Ni-O backscattering pairs. The second coordination shell was fitted solely using Ni-Ni pairs, because the discrimination of $\mathrm{Ni}-\mathrm{Ni}$ and $\mathrm{Ni}-\mathrm{Al}$ backscattering pairs in $\mathrm{Ni}-\mathrm{Al} \mathrm{LDH}$ is problematic $[3,4]$. To be able to compare the coordination numbers $(\mathrm{CN})$ of the Ni-Ni backscattering pairs $\left(\mathrm{CN}_{\mathrm{Ni}-\mathrm{Ni}}\right)$ of all samples and references, the Debye-Waller factor was set to $0.005 \AA^{2}$. This value was determined from the fitting of the $\beta-\mathrm{Ni}(\mathrm{OH})_{2}$ spectrum. Data analysis reveals similar $\mathrm{CN}$ and interatomic distances $(\mathrm{R})$ for all spots. The first FT peak corresponds to an octahedral coordination of $\mathrm{Ni}$ with $\sim 6$ oxygen atoms at 2.05-2.06 $\AA$. The second FT peak reveals strongly reduced $\mathrm{CN}_{\mathrm{Ni}-\mathrm{Ni}}(\sim 3)$ compared to $\alpha-\mathrm{Ni}(\mathrm{OH})_{2}(\sim 5)$ [16] and $\beta-\mathrm{Ni}(\mathrm{OH})_{2}(\sim 6)$ [17]. The $\mathrm{CN}_{\mathrm{Ni}-\mathrm{Ni}}$ values of the experimental spectra are comparable to those determined for Ni-Al LDH. The $\mathrm{CN}_{\mathrm{Ni}-\mathrm{Ni}}$ is reduced as $\mathrm{Ni}$ is partly substituted by $\mathrm{Al}$ in Ni-Al LDH. This causes a significant destructive interference between $\mathrm{Ni}$ and Al EXAFS contributions, which results in an amplitude cancellation of the $\mathrm{Ni}$ and $\mathrm{Al}$ shells $[5,15]$. Although the $\mathrm{CN}_{\mathrm{Ni}-\mathrm{Ni}}$ of the single spots of the Ni-doped HCP sample and $\mathrm{Ni}-\mathrm{Al} \mathrm{LDH}$ agree very well, the overall Ni-Ni distances, especially of spot 2 and 3 $(3.10 \AA)$, are longer than those in Ni-Al LDH (3.06-3.07 $\AA$ ). This finding suggests that, in addition to $\mathrm{Ni}-\mathrm{Al} \mathrm{LDH}$, other Ni-containing phases are present. The longer $\mathrm{R}_{\mathrm{Ni}-\mathrm{Ni}}$ is attributed to the presence of $\beta-\mathrm{Ni}(\mathrm{OH})_{2}$ impurities $\left(\mathrm{R}_{\mathrm{Ni}-\mathrm{Ni}}=3.13 \AA\right)$ [5]. Based on thermodynamic calculations, $\beta-\mathrm{Ni}(\mathrm{OH})_{2}$ is expected to precipitate in the Ni-doped $\mathrm{HCP}$ samples, since at high $\mathrm{pH}$ the system is oversaturated with respect to this phase [18]. The findings from the $\mu$-EXAFS investigations indicate that at single $\mathrm{Ni}$ spots mainly $\mathrm{Ni}-\mathrm{Al}$ $\mathrm{LDH}$ is formed, independent of the hydration time, and that only at some Ni spots small amounts of $\beta-\mathrm{Ni}(\mathrm{OH})_{2}$ are formed. Linear combination (LC) of the experimental spectra of the single spots fitted with the reference compounds $\left(\alpha-\mathrm{Ni}(\mathrm{OH})_{2}, \beta-\mathrm{Ni}(\mathrm{OH})_{2}, \mathrm{Ni}-\mathrm{Al}\right.$ $\mathrm{LDH}$ ) indicate that at all single spots $\mathrm{Ni}-\mathrm{Al} \mathrm{LDH}$ is, indeed, the predominant phase formed, together with Ni-hydroxides ( 40-50\%). The Ni-hydroxides phase predominantly observed in the cement matrix was $\alpha-\mathrm{Ni}(\mathrm{OH})_{2}$, regardless of the hydration time. Additionally, $\beta-\mathrm{Ni}(\mathrm{OH})_{2}$ was found at single spots (spots 2 and 3 ) in the HCP sample hydrated for six hours.

The results from the micro-scale study can be compared with those from earlier macro-scale investigation [5]. The macro-scale (bulk-EXAFS) investigations explicitly revealed the formation of a mixture of $\mathrm{Ni}-\mathrm{Al} \mathrm{LDH}, \alpha-\mathrm{Ni}(\mathrm{OH})_{2}$ and $\beta-\mathrm{Ni}(\mathrm{OH})_{2}$ [5], for all hydration times. Furthermore, this earlier study demonstrated that the composition of the mixture varied with the hydration time. In particular, it showed that the amount of Ni-Al $\mathrm{LDH}$ was found to increase with increasing hydration time, whereas $\alpha-\mathrm{Ni}(\mathrm{OH})_{2}$ decreased and $\beta-\mathrm{Ni}(\mathrm{OH})_{2}$ remained constant. The $\mu$-EXAFS experimental results presented in this study show that at single Ni-rich spots the same Ni phases precipitate, i.e., predominantly Ni-Al LDH and some Ni-hydroxides. In the earlier study of Vespa et al. [5], the predominant Ni-hydroxide phase formed upon short hydration time was $\alpha-\mathrm{Ni}(\mathrm{OH})_{2}$, whereas $\beta-\mathrm{Ni}(\mathrm{OH})_{2}$ was found to be the dominant Ni-hydroxide after longer hydration time. The micro-scale results appear to contradict this finding, since at short and long hydration time $\alpha-\mathrm{Ni}(\mathrm{OH})_{2}$ was the predominant Ni-hydroxide phase observed. This indicates that $\mu$-EXAFS measurements on a few spots may not necessarily be representative 


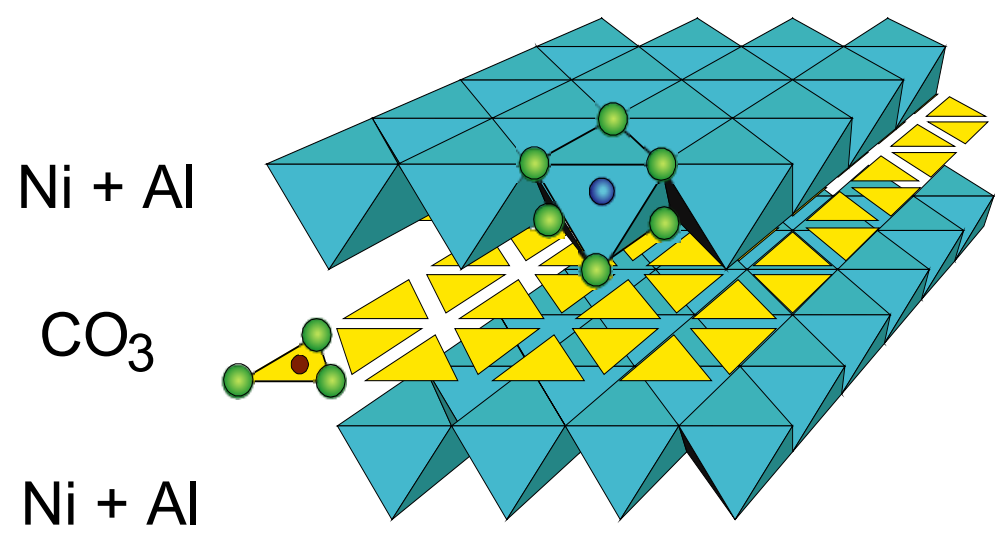

Fig. 3. Structural model of Ni-Al LDH. The centres of the octahedra are filled with $\mathrm{Ni}$ and Al. The interlayer position can be filled with different anions such as $\mathrm{CO}_{3}{ }^{2-}, \mathrm{NO}_{3}{ }^{-}, \mathrm{Cl}^{-}, \mathrm{SO}_{4}{ }^{2-}$

to the whole matrix. Therefore, it is essential to complement micro-scale with macroscale investigations to gain the full picture.

Based on both bulk- and $\mu$-EXAFS results the following structural model for the Ni-Al LDH phase (Fig. 3) is proposed. Ni-Al layered double hydroxides are hydrotalcite-type phases commonly expressed as $\left.\left[\mathrm{M}_{1-\mathrm{x}}^{\mathrm{II}} \mathrm{M}^{\mathrm{III}}(\mathrm{OH})_{2}\right]^{\mathrm{x}+}\left(\mathrm{A}^{\mathrm{n}-}\right)_{\mathrm{X} / \mathrm{n}^{n}} \cdot \mathrm{yH}_{2} \mathrm{O}\right)$. The $\mathrm{M}^{\mathrm{II}}$ position can be filled with several bivalent metal cations (e.g., $\mathrm{Mg}, \mathrm{Mn}, \mathrm{Fe}, \mathrm{Co}, \mathrm{Ni}, \mathrm{Zn}$ ), the $\mathrm{M}^{\mathrm{III}}$ position with trivalent metal cations (e.g., $\mathrm{Al}, \mathrm{Cr}, \mathrm{Fe}$ ) and the $\mathrm{A}^{\mathrm{n}-}$ position with different anions such as $\mathrm{CO}_{3}{ }^{2-}, \mathrm{NO}_{3}{ }^{-}, \mathrm{Cl}^{-}, \mathrm{SO}_{4}{ }^{2-}$. In this study we propose that, the $\mathrm{M}^{\mathrm{II}}$ and $\mathrm{M}^{\mathrm{III}}$, which lie at the centre of the octahedra, are partially filled with $\mathrm{Ni}$ and $\mathrm{Al}$.

Acknowledgement: The staff of the Beamline 10.3.2 at the ALS and of the Swiss Norwegian Beamline (SNBL) at the ESRF is thanked for the experimental assistance during the synchrotron-based investigations. Thanks are extended to Dr. E. Curti, D. Kunz, Dr. M. Harfouche for assistance during the measuring campaigns. Dr. C.A. Johnson (EAWAG, Switzerland) is warmly thanked for the Ni-Al LDH reference compounds. Prof. B. Wehrli (EAWAG, Switzerland) is gratefully acknowledged for fruitful discussions and constructive comments. Partial financial support was provided by the National Cooperative for the Disposal of Radioactive Waste (Nagra), Switzerland.

\section{References}

[1] Chapman N. and McCombie C.: Principles and standards for the disposal of long-lived radioactive wastes; 1st Ed.; Elsevier Science, Ltd., Oxford, 2003; Vol. 3.

[2] Glasser F. P.: Chemistry of cement-solidified waste forms. In: Chemistry and microstructure of solidified waste forms, Spence, R. D. (Ed.), Lewis Publishers, Boca Raton, 1993, pp 1-39.

[3] Scheidegger A., Wieland E., Dähn R. and Spieler P.: Environmental Science and Technology 34 (2000) 4545. 
[4] Scheidegger A. M. et al.: Journal of Synchrotron Radiation 8 (2001) 916.

[5] Vespa M., Dähn R., Grolimund D., Wieland E. and Scheidegger A. M.: Environmental Science and Technology 40 (2006) 2275.

[6] Vespa M. et al.: Environmental Science and Technology (2006) in press.

[7] Döhring L., Görlich W., Rüttener S. and Schwerzmann R.: Nagra NIB 94-29 (1994).

[8] Lothenbach B. and Wieland E.: Waste Management (2006) 26, 706.

[9] Marcus, M. et al.: Journal of Synchrotron Radiation 11 (2004) 239.

[10] Ressler, T.: Journal of Synchrotron Radiation 5 (2) (1998) 118.

[11] Rehr J. J., Mustre de Leon J., Zabinsky S. I., and Albers, R. C.: Journal of the American Chemical Society 113 (1991) 5135.

[12] Johnson C. A. and Glasser F. P.: Clays and Clay Minerals 51 (2003) 1.

[13] Dähn R. et al.: Geochimica et Cosmochimica Acta 66 (13) (2002) 2335.

[14] Scheidegger A. M., Lamble G. M. and Sparks, D. L.: Journal de Physique IV France 7 (C2) (1997) 773.

[15] Scheinost A. C. and Sparks D. L.: Journal of Colloid and Interface Science 223 (2000) 1.

[16] Bode H., Dehmelt K. and Witte J.: Electrochimica Acta 11 (1966) 1079.

[17] Mansour A. N. and Melendres C. A.: Journal of Physical Chemistry A 102 (1998) 65.

[18] Hummel W. and Curti E.: Monatshefte für Chemie 134 (2003) 941. 